\title{
A new form of $\mathrm{MgTa}_{2} \mathrm{O}_{6}$ obtained by the molten salt method
}

\author{
ASHOK K GANGULI, ${ }^{a} *$ SHIKHA NANGIA, ${ }^{a}$ MEGANATHAN THIRUMAL ${ }^{\mathrm{a}}$ and \\ PRATIBHA L GAI \\ ${ }^{a}$ Department of Chemistry, Indian Institute of Technology, New Delhi 110016 \\ ${ }^{b}$ DuPont, Central Research and Development, Wilmington, DE 19880-0356 and University of Delaware, \\ Newark, Delaware, 19716, USA \\ e-mail: ashok@chemistry.iitd.ernet.in
}

\begin{abstract}
Using molten salt route (with $\mathrm{NaCl} / \mathrm{KCl}$ as the salt) we have been able to synthesize a new form of magnesium tantalate at $850^{\circ} \mathrm{C}$. Powder X-ray diffraction data could be indexed on an orthorhombic unit cell with lattice parameters, ' $a$ ' $=15 \cdot 36(1) \AA,{ }^{\prime} b$ ' $=13 \cdot 38(1) \AA$ and ' $c$ ' $=12 \cdot 10(1) \AA$. High resolution transmission electron microscopy and electron diffraction studies confirm the results obtained by X-ray studies. Energy dispersive X-ray spectroscopy helps ascertain the composition of $\mathrm{MgTa}_{2} \mathrm{O}_{6}$. The title compound shows a dielectric constant of $\sim 24$ with a low dielectric loss of 0.006 at $100 \mathrm{kHz}$ at room temperature. Dielectric constant is nearly unchanged with rise in temperature while the loss shows a very marginal increase $\left(0.007\right.$ at $\left.300^{\circ} \mathrm{C}\right)$.
\end{abstract}

Keywords. $\mathrm{MgTa}_{2} \mathrm{O}_{6}$; molten salt method; high resolution transmission electron microscopy; dielectric properties.

\section{Introduction}

Perovskite-related oxides of $\mathrm{Nb}$ and $\mathrm{Ta}$, for example $\mathrm{Ba}_{3} \mathrm{MgNb}_{2} \mathrm{O}_{9}, \mathrm{Ba}_{3} \mathrm{MgTa}_{2} \mathrm{O}_{9}$ and $\mathrm{Ba}_{3} \mathrm{ZnTa}_{2} \mathrm{O}_{9}$, have generated considerable research interest because of their application as dielectric resonators at microwave frequencies. ${ }^{1-3}$ In addition to the above perovskite related oxides, another class of oxides containing $\mathrm{Nb}$ or $\mathrm{Ta}$ and having the $\mathrm{AB}_{2} \mathrm{O}_{6}$ composition have been investigated for their microwave dielectric properties recently. ${ }^{4-6}$ Here ' $A$ ' is normally an alkaline earth metal and ' $\mathrm{B}$ ' is $\mathrm{Nb}$ or Ta. Most niobates have the columbite structure while tantalates have a variety of related structures depending on the ' $\mathrm{A}$ ' cation.

$\mathrm{MgTa}_{2} \mathrm{O}_{6}$ is an interesting dielectric material and has uses in the microwave frequency range. It has been reported (JCPDS \# 84-1679) to crystallize in the trirutile structure with space group of $P 4_{2} / \mathrm{mnm}$ and tetragonal lattice parameters of ' $a$ ' $=4 \cdot 7189(7) \AA$ and ' $c$ ' $=9 \cdot 2003(22) \AA$. The structure is made up of strings of edge-shared octahedra, extending along the ' $c$ ' direction and these strings are linked to each other by sharing corners. The edge-sharing occurs at opposite edges in each octahedron and leads to linear octahedral strings in the trirutile structure. Normally the synthesis of $\mathrm{MgTa}_{2} \mathrm{O}_{6}$ by the ceramic route

Dedicated to Prof J Gopalakrishnan on his 62nd birthday

*For correspondence is carried out at high temperatures of $1200^{\circ} \mathrm{C}$ to $1400^{\circ} \mathrm{C}$. The above structure can be obtained ${ }^{7}$ by the ceramic route by heating $\mathrm{Mg}\left(\mathrm{NO}_{3}\right)_{2} \cdot 6 \mathrm{H}_{2} \mathrm{O}$ and $\mathrm{Ta}_{2} \mathrm{O}_{5}$ at temperatures of $1200^{\circ} \mathrm{C}$. It may be noted that using $\mathrm{MgO}$ as the starting material leads to a biphasic mixture ${ }^{8}$ of $\mathrm{MgTa}_{2} \mathrm{O}_{6}$ and $\mathrm{Ta}_{2} \mathrm{O}_{5}$ at $1200^{\circ} \mathrm{C}$.

Due to the high temperatures of reaction required for most of the niobates and especially the tantalates, we have been interested in the synthesis of these oxides by alternate low temperature routes. The molten salt route has been used earlier ${ }^{9-13}$ to obtain several important oxides at a much lower temperature than that required by the ceramic route. Our investigation using $\mathrm{NaCl} / \mathrm{KCl}$ as the salt and starting with $\mathrm{Mg}\left(\mathrm{NO}_{3}\right)_{2} \cdot 6 \mathrm{H}_{2} \mathrm{O}$ and $\mathrm{Ta}_{2} \mathrm{O}_{5}$ led to the synthesis of a new orthorhombic modification of $\mathrm{MgTa}_{2} \mathrm{O}_{6}$. In this paper, we report the synthesis and detailed structural characterization by combined powder X-ray diffraction, electron diffraction, energy dispersive X-ray spectroscopy and high resolution electron microscopy. We also report the dielectric properties of this new form of $\mathrm{MgTa}_{2} \mathrm{O}_{6}$, in the frequency range of $50 \mathrm{~Hz}$ to $500 \mathrm{kHz}$ and in the temperature range of $35^{\circ}$ to $300^{\circ} \mathrm{C}$.

\section{Experimental}

To stoichiometric amounts of $\mathrm{Mg}\left(\mathrm{NO}_{3}\right)_{2} \cdot 6 \mathrm{H}_{2} \mathrm{O}$ (Merck, 99\%) and $\mathrm{Ta}_{2} \mathrm{O}_{5}$ (Aldrich, 99\%), a 1:1 mixture 
of $\mathrm{NaCl}$ (BDH, 99.5\%) and $\mathrm{KCl}$ (Qualigens, 99.5\%) was added to act as the molten salt or flux. The ratio of reactants to flux was taken as $2: 1$. These were homogenized by grinding manually in an agate mortar and then heated at $850^{\circ} \mathrm{C}$ for $6 \mathrm{~h}$. The product was then washed thoroughly with distilled water and checked for $\mathrm{Cl}^{-}$ions in the filtrate. This was to make sure that all the flux was washed off. The powder was then dried at $120^{\circ} \mathrm{C}$. The resulting powder was ground, mixed with PVA (polyvinyl alcohol) and compacted into disks at a pressure of 4 tons. The disks were then sintered at $1100^{\circ} \mathrm{C}$ for $28 \mathrm{~h}$ with one intermittent grinding for the dielectric measurements. Further sintering at $1200^{\circ} \mathrm{C}$ for $12 \mathrm{~h}$ was carried out to observe changes in the structure, if any. Powder X-ray diffraction (PXRD) was obtained after each step with a Bruker D8 Advance diffractometer with $\mathrm{Cu}-\mathrm{K} \alpha$ radiation. A step size of 0.05 with step time of 1 second was used for the 2-theta range of 10 to 70 degrees. The raw data were subjected to background correction and $\mathrm{K} \alpha_{2}$ stripping. A combination of electron diffraction and high resolution transmission electron microscopy was carried out to confirm the lattice parameters (obtained from PXRD). Electron microscopy was carried out on FEI CM30 HRTEM. Low electron doses were employed ${ }^{14,15}$ due to the samples being beam-sensitive. Using accelerating voltages of $200 \mathrm{kV}$, we have succeeded in high resolution imaging and electron diffraction measurements of the compound. Crystals were tilted to different zone axis including the [10-1] and [12-1] projections. High precision compositional analysis was carried out simultaneously using energy dispersive X-ray spectroscopy (EDX) in the HRTEM. In addition, scanning electron micrographs (SEM) were obtained on a Cambridge Stereoscan 360 electron microscope to observe the morphology of the grains obtained. The dielectric constant was measured on sintered disks $\left(1100^{\circ} \mathrm{C}\right)$ coated with silver using a HP $4284 \mathrm{~L} \mathrm{LCR}$ meter in the frequency range of $50 \mathrm{~Hz}$ to $500 \mathrm{kHz}$. Temperature variation studies of the dielectric constant and dielectric loss was carried out in the range of $35^{\circ}$ to $300^{\circ} \mathrm{C}$. The density of the sintered disks was obtained by the Archimedes principle using carbon tetrachloride as solvent and was found to be $92 \%$ of the theoretical density.

\section{Results and discussion}

Powder X-ray diffraction studies of the sample heated at $850^{\circ} \mathrm{C}$ suggests an altogether different phase as

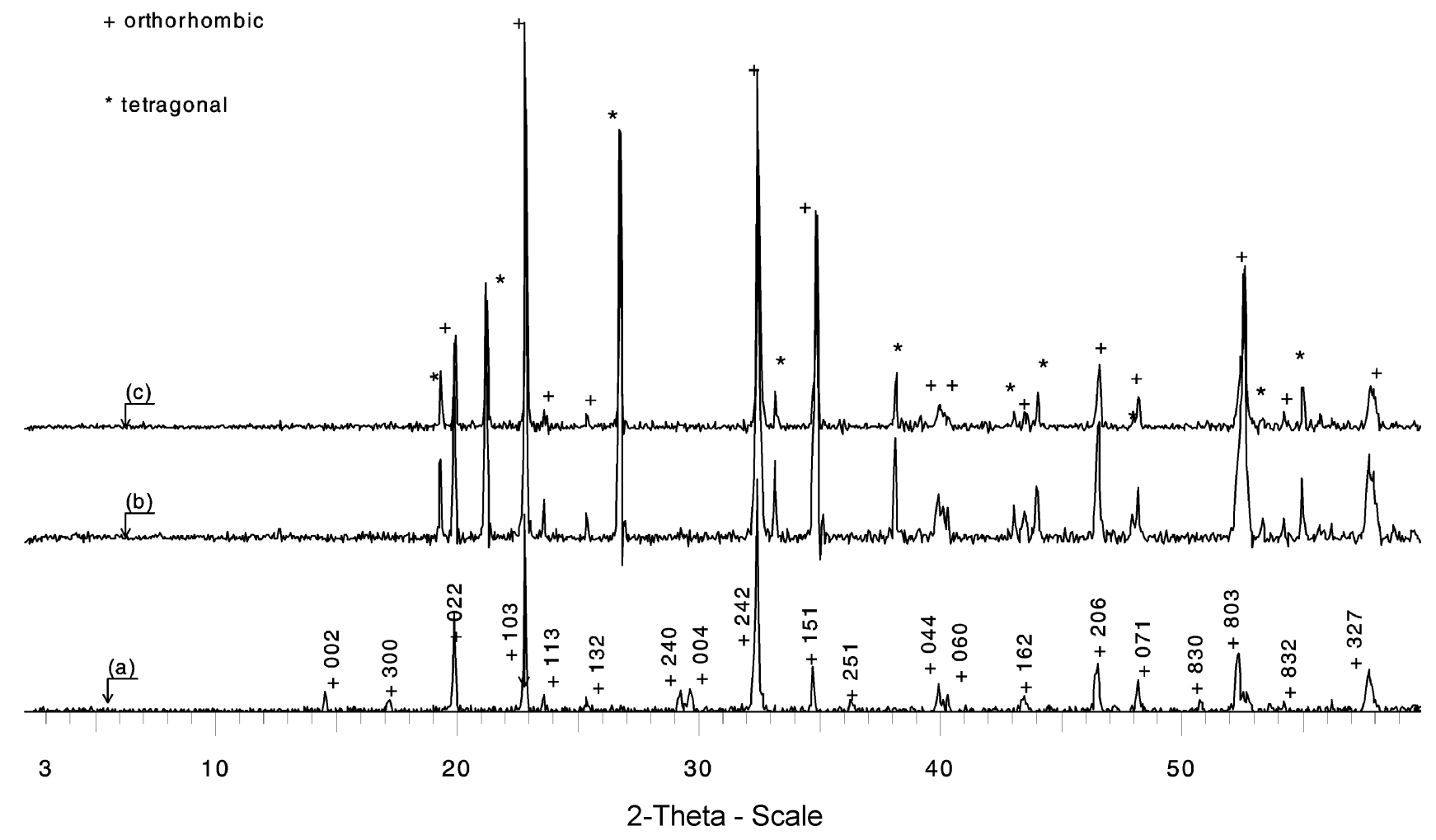

Figure 1. Powder X-ray diffraction pattern of $\mathrm{MgTa}_{2} \mathrm{O}_{6}$ heated at (a) $850^{\circ} \mathrm{C}$ for 6 hours, (b) $1100^{\circ} \mathrm{C}$ for 16 hours and (c) $1200^{\circ} \mathrm{C}$ for 12 hours. 

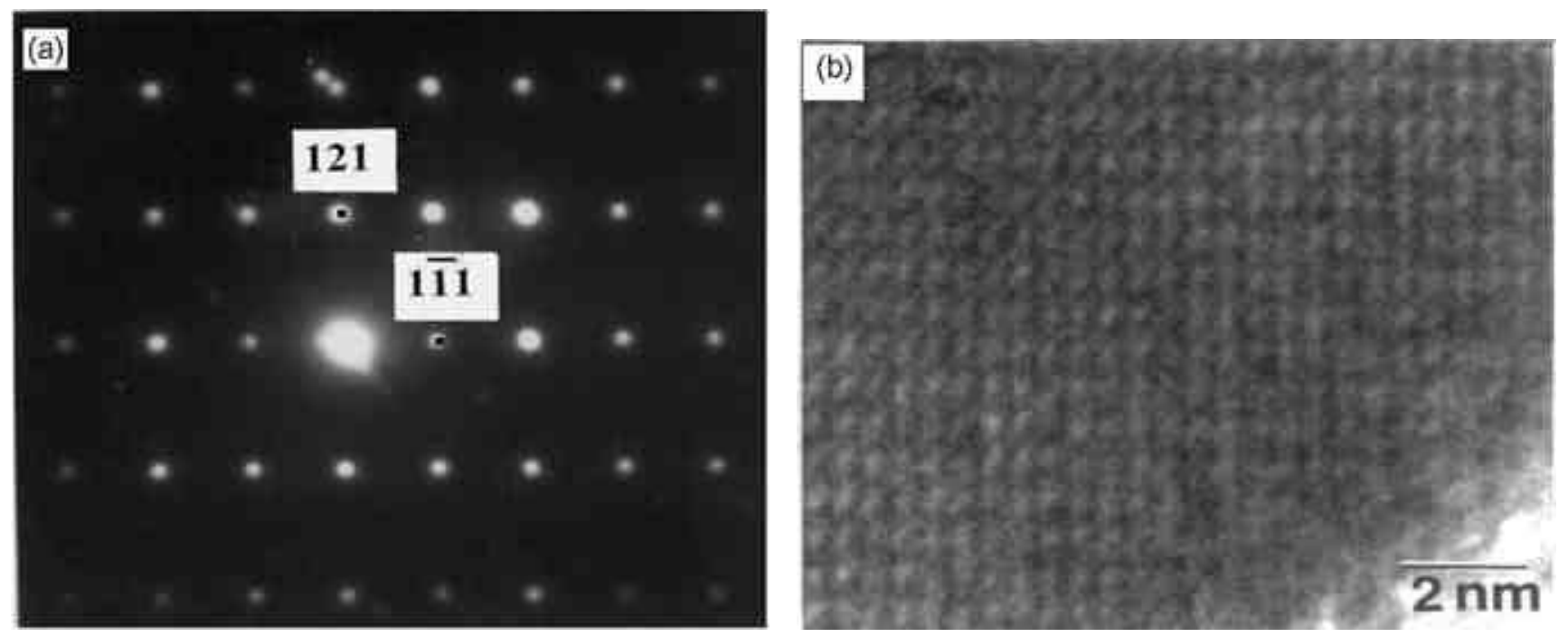

Figure 2. (a) [10-1] Electron diffraction pattern of $\mathrm{MgTa}_{2} \mathrm{O}_{6}$ and (b) the corresponding lattice image.

compared to the reported tetragonal form (JCPDS \# 84-1679) of $\mathrm{MgTa}_{2} \mathrm{O}_{6}$ (figure 1a). All the reflections in the diffraction pattern can be indexed on the basis of an orthorhombic phase with refined lattice parameters (as obtained by a least squares fit to the observed $d$ values) of ' $a$ ' $=15 \cdot 36(1) \AA,{ }^{\prime} b '=13 \cdot 38(1) \AA$ and ' $c$ ' $=12 \cdot 10(1) \AA$. After sintering at $1100^{\circ} \mathrm{C}$ for $16 \mathrm{~h}$, it is observed that the PXRD pattern becomes sharper and that there is considerable change in the intensity of some of the reflections (figure 1b). The 200, 003, 042,400 and 152 reflections disappear while 122, 024, 421, 151 and 308 lines become more pronounced after sintering. It is to be noted that these reflections also belong to the smaller tetragonal cell known for $\mathrm{MgTa}_{2} \mathrm{O}_{6}$. Reflections at $d$-values of 4.19 and $2.70 \AA$, which are absent earlier, can be seen clearly after sintering. These reflections can be indexed only on the basis of the tetragonal $\mathrm{MgTa}_{2} \mathrm{O}_{6}$, and not on the basis of the orthorhombic cell. It is thus clear from the X-ray diffraction that there is phase transformation into the tetragonal form of $\mathrm{MgTa}_{2} \mathrm{O}_{6}$ from orthorhombic $\mathrm{MgTa}_{2} \mathrm{O}_{6}$ resulting in a mixture of two phases. No change is observed in the PXRD pattern after sintering at $1100^{\circ}$ and $1200^{\circ} \mathrm{C}$ for a further period of $24 \mathrm{~h}$ with one intermittent grinding (figure 1c). Attempts to synthesize $\mathrm{MgTa}_{2} \mathrm{O}_{6}$ using the ceramic route with $\mathrm{MgO}$ and $\mathrm{Ta}_{2} \mathrm{O}_{5}$ as the starting material, ${ }^{8}$ led to the tetragonal structure (' $a$ ' $=4 \cdot 714(2) \AA$, ' $c$ ' $=9 \cdot 199(5) \AA$ and space group $P 4_{2} / \mathrm{mnm}$ ) with considerable amounts of $\mathrm{Ta}_{2} \mathrm{O}_{5}(37 \%)$ as impurity. However the use of $\mathrm{Mg}\left(\mathrm{NO}_{3}\right)_{2} \cdot 6 \mathrm{H}_{2} \mathrm{O}$ instead of $\mathrm{MgO}$ as one of the reactants in the ceramic route ${ }^{7}$ leads to monophasic $\mathrm{MgTa}_{2} \mathrm{O}_{6}$ with tetragonal lattice parameters of ' $a$ ' $=4.695(2) \AA$, ' $c$ ' $=9 \cdot 147(5) \AA$. There is no evidence of the orthorhombic phase by the above solid-state synthesis. Thus the molten salt route as reported here using $\mathrm{Mg}\left(\mathrm{NO}_{3}\right)_{2} \cdot 6 \mathrm{H}_{2} \mathrm{O}$ and $\mathrm{Ta}_{2} \mathrm{O}_{5}$ along with the flux $(\mathrm{NaCl}-\mathrm{KCl})$ leads to this new orthorhombic modification of $\mathrm{MgTa}_{2} \mathrm{O}_{6}$.

Our electron diffraction data on the sample before sintering corroborates well with the results obtained from PXRD. Electron diffraction data show an orthorhombic phase indexed with approximate lattice parameters of ' $a$ ' $\sim 15.4 \AA$, ' $b$ ' $\sim 13.4 \AA$ and ' $c$ ' $~$ $12 \cdot 2 \AA$. The electron diffraction pattern in the [10-1] projection is shown in figure $2 \mathrm{a}$ and the corresponding lattice image is shown in figure $2 \mathrm{~b}$. EDX compositional analysis of the oxide supported on Ti grid is shown in figure 3a. The analysis supports the composition of $\mathrm{MgTa}_{2} \mathrm{O}_{6}$. The presence of [12-1] zone axis is also observed in the electron microscopic investigations. The electron diffraction pattern and the corresponding HRTEM image with the surface layers is illustrated in figure $3 \mathrm{~b}$. The crystal axes and the reflections of -222 and 202 (at $m$ ) are indicated on the diffraction pattern and the faint reflections are arrowed. Lattice parameters are as described above. Both the electron diffraction patterns and HRTEM images demonstrate well-ordered atomic periodicity in the material.

The orthorhombic lattice parameters may be related to the tetragonal trirutile cell known for $\mathrm{MgTa}_{2} \mathrm{O}_{6}$ in the following way: $a_{\text {ortho }}=(5 / 3) c_{\text {tet }} ; b_{\text {ortho }}=(2 \sqrt{2}) a_{\text {tet }}$; $c_{\text {ortho }}=(4 / 3) c_{\text {tet }}$. In the tetragonal phase the $\mathrm{Mg}$ and 
Ta ions are ordered along the $c$-axis as $-\mathrm{Mg}-\mathrm{Ta}-\mathrm{Ta}-$ $\mathrm{Mg}-$ (figure $4 \mathrm{a}$ ). The distance between two successive layers along the tetragonal $c$-axis is $\sim(1 / 3) c_{\text {tet }}$. Thus a distance of $4 / 3 c_{\text {tet }}$ or $5 / 3 c_{\text {tet }}$ may be conceived as adding one or two more metal-oxygen layers respectively to the original tetragonal $c$-axis which would then correspond to the orthorhombic $c$ - and $a$ axis (figures $4 \mathrm{~b}$ and $\mathrm{c}$ ). However, the new layers added would have to be made up of both $\mathrm{Mg}$ and $\mathrm{Ta}$ in the ratio of $1: 2$ to maintain the overall stoichiometry of $\mathrm{MgTa}_{2} \mathrm{O}_{6}$. Thus the layer sequence along the orthorhombic $a$-axis will be $-\mathrm{Mg}-\mathrm{Ta}-(0 \cdot 33 \mathrm{Mg} /$ $0.66 \mathrm{Ta})-(0.33 \mathrm{Mg} / 0.66 \mathrm{Ta})-\mathrm{Ta}-\mathrm{Mg}-$ and the layer sequence along the orthorombic $c$-axis may be $-\mathrm{Mg}_{-}$ $\mathrm{Ta}-(0.33 \mathrm{Mg} / 0 \cdot 66 \mathrm{Ta})-\mathrm{Ta}-\mathrm{Mg}-$. The trirutile struc-

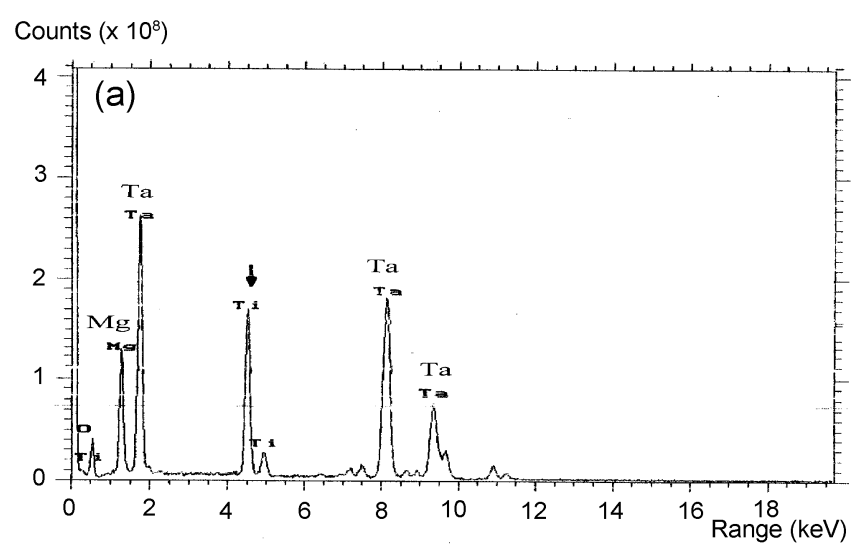

(b)
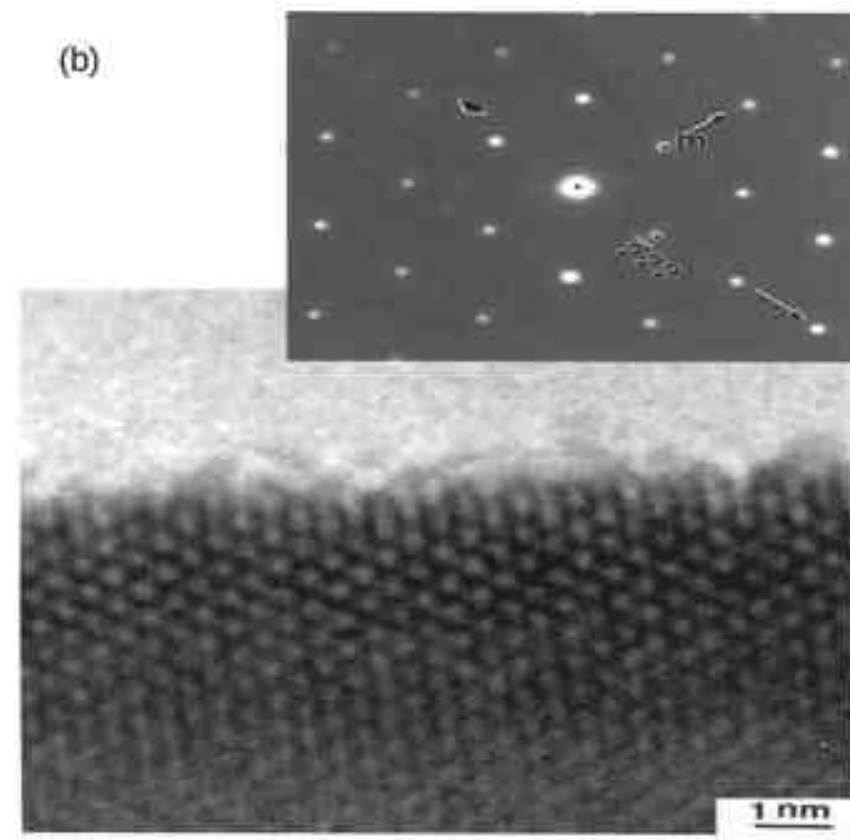

Figure 3. (a) EDX compositional analysis of $\mathrm{MgTa}_{2} \mathrm{O}_{6}$ and (b) the presence of [12-1] zone axis image as seen by HRTEM. ture of tetragonal $\mathrm{MgTa}_{2} \mathrm{O}_{6}$ is made up of strings of edge-shared octahedra, extending along the ' $c$ ' direction and these strings are linked to one another by sharing corners. Edge-sharing occurs at opposite edges in each octahedron and leads to linear octahedral strings extending infinitely. However, in case of the orthorhombic structure which is of lower symmetry,

(a)

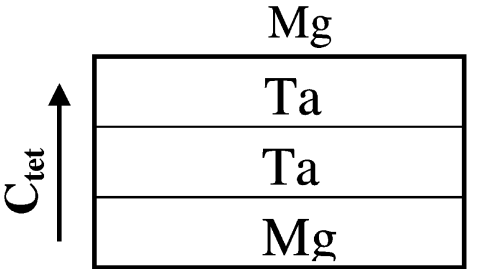

(c)

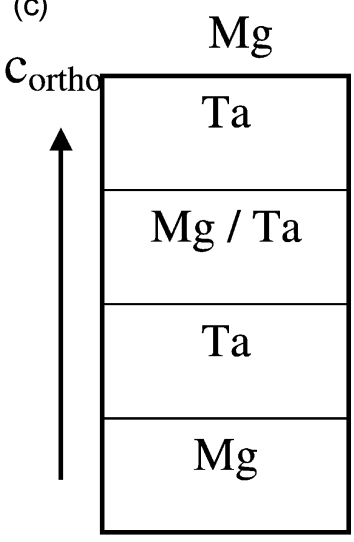

$\mathrm{Mg}$

(b)

\begin{tabular}{|c|c|}
\hline \multirow[t]{5}{*}{$a_{\text {ortho }}$} & $\mathrm{Ta}$ \\
\hline & $\mathrm{Mg} / \mathrm{Ta}$ \\
\hline & $\mathrm{Mg} / \mathrm{Ta}$ \\
\hline & $\mathrm{Ta}$ \\
\hline & $\mathrm{Mg}$ \\
\hline
\end{tabular}

Figure 4. Schematic layer sequence showing the arrangement of the $\mathrm{Mg}$ and Ta layers in $\mathrm{MgTa}_{2} \mathrm{O}_{6}$ (a) tetragonal (b) orthorhombic along the $a$-axis and (c) along the orthorhombic $c$-axis.

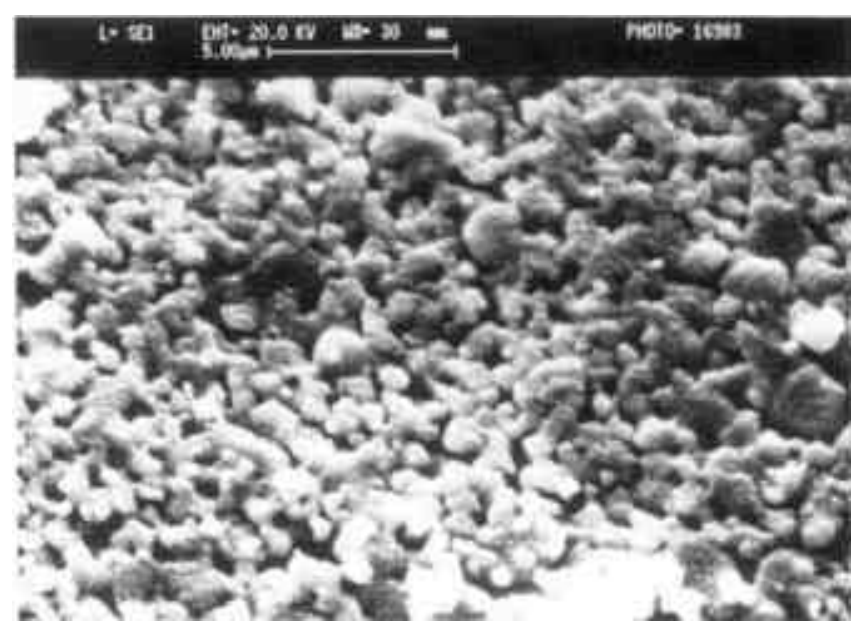

Figure 5. Scanning electron micrograph of $\mathrm{MgTa}_{2} \mathrm{O}_{6}$. 


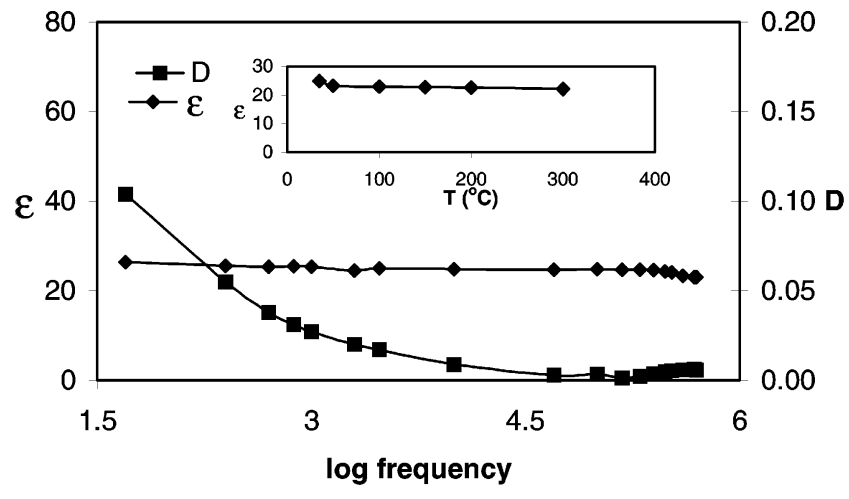

Figure 6. Variation of dielectric constant and dielectric loss with frequency at room temperature for $\mathrm{MgTa}_{2} \mathrm{O}_{6}$. Inset shows the variation of dielectric constant with temperature at $100 \mathrm{kHz}$.

this infinite linear chain of octahedra has to be truncated and instead we would have chains with finite number of octahedra arranged in an ordered fashion. A large number of complex metal tantalates/titanates having relation to $\mathrm{BaTa}_{2} \mathrm{O}_{6}$ and $\mathrm{Ba}_{5} \mathrm{Ta}_{4} \mathrm{O}_{15}$ have been reviewed recently. ${ }^{16}$ The structures show different stacking sequences of layers comprising edge-shared octahedra. We believe that this $\mathrm{MgTa}_{2} \mathrm{O}_{6}$ structure may have close relation to some of the above structures. The exact structure of orthorhombic $\mathrm{MgTa}_{2} \mathrm{O}_{6}$ obtained by us would require further study preferably by single-crystal X-ray diffraction.

Scanning electron microscopy photographs (figure 5) show that the oxide particles are between 0.5 and $1.0 \mu \mathrm{m}$ in size and are spherical in shape. The grains are well defined and densely packed. These studies were carried out on samples sintered at $1100^{\circ} \mathrm{C}$ for $16 \mathrm{~h}$.

Measurements of dielectric properties have been carried out on compacted disks sintered at $1100^{\circ} \mathrm{C}$. The variation of dielectric constant with frequency in the range $50 \mathrm{~Hz}$ to $500 \mathrm{kHz}$ at room temperature has been shown in figure 6 . It is found that the dielectric constant is stable over a large range of frequency from $500 \mathrm{~Hz}$ to $500 \mathrm{kHz}$. The dielectric constant varies from 25 at $500 \mathrm{~Hz}$ to 23 at $500 \mathrm{kHz}(\mathrm{d} \varepsilon / \mathrm{d} F=$ $\left.4 \times 10^{-6} \mathrm{~Hz}^{-1}\right)$. The dielectric loss shows a fall till $50 \mathrm{kHz}$, beyond which it is very low and has a value of 0.006 till $500 \mathrm{kHz}$. In an earlier study ${ }^{7}$ the dielectric constant of $\mathrm{MgTa}_{2} \mathrm{O}_{6}$ prepared by the ceramic route was reported to be 28 . The dielectric constant of $\mathrm{MgTa}_{2} \mathrm{O}_{6}$ in the microwave frequency range is reported $^{6}$ at $30 \cdot 3$. However, it must be noted that the dielectric properties measured were for the mixture of the two phases, namely the orthorhombic and tetragonal form of $\mathrm{MgTa}_{2} \mathrm{O}_{6}$. This suggests that the orthorhombic phase has a slightly lower dielectric constant compared to that of the tetragonal $\mathrm{MgTa}_{2} \mathrm{O}_{6}$ normally obtained by the ceramic route. Also, the stability of the dielectric constant with frequency of orthorhombic $\mathrm{MgTa}_{2} \mathrm{O}_{6}$ is as good as that known for the tetragonal form.

We have also studied the variation of dielectric constant as a function of temperature in the range of $35^{\circ}$ to $300^{\circ} \mathrm{C}$ (inset of figure 6). Dielectric constant decreases from 24 to 22 at $100 \mathrm{kHz}$ as the temperature is increased from $35^{\circ}$ to $300^{\circ} \mathrm{C}$. Thus the temperature coefficient of dielectric constant at this frequency is $\mathrm{d} \varepsilon / \mathrm{d} T=-0 \cdot 075 /{ }^{\circ} \mathrm{C}$. The dielectric loss at $100 \mathrm{kHz}$ decreases from 0.0035 to 0.0023 as the temperature rises from $35^{\circ}$ to $300^{\circ} \mathrm{C}$. So we may conclude that the dielectric properties of the orthorhombic phase are also temperature stable.

\section{Conclusion}

We have synthesized a new form of magnesium tantalate using a molten salt route. It crystallizes in the orthorhombic structure, which has been proved by powder X-ray diffraction and HRTEM. At higher temperatures the orthorhombic phase transforms to the known tetragonal form of $\mathrm{MgTa}_{2} \mathrm{O}_{6}$. This new orthorhombic form of magnesium tantalate has a slightly lower dielectric constant of 24 (compared to the tetragonal form) and a very low dielectric loss of 0.0035 at room temperature at $100 \mathrm{kHz}$.

\section{Acknowledgement}

The work was financially supported by the Council for Scientific and Industrial Research (CSIR), New Delhi.

\section{References}

1. Nomura S, Toyama T and Kaneta K 1982 Jpn. J. Appl. Phys. 21 L642

2. Kawashima S, Nishida M, Ueda I and Ouchi H 1983 J. Am. Ceram. Soc. 66421

3. Tamura H, Konoike T, Sakabe Y and Wakino K 1984 J. Am. Ceram. Soc. 67 C59

4. Maeda M, Yamamura T and Ikeda T 1987 Jpn. J. Appl. Phys. Supp. 2676

5. Lee H J, Hong K S, Kim S J and Kim I T 1997 Mater. Res. Bull. 32847 
6. Lee H J, Kim I T and Hong K S 1997 Jpn. J. Appl. Phys. 36 L1318

7. Thirumal M and Ganguli A K 2001 Mater. Res. Bull. 362421

8. Thirumal M and Ganguli A K 2001 Proc. Ind. Acad. Sci. 113603

9. Arendt R H 1973 J. Solid State Chem. 8339

10. Arendt R H, Rosolowski J H and Szmaszek J W 1979 Mater. Res. Bull. 14703

11. Granahan M, Holmes M, Schulze W A and Newnham R E 1982 J. Am. Ceram. Soc. 6468
12. Thirumal M, Jain P and Ganguli A K 2001 Mater. Chem. Phys. 707

13. Ganguli A K, Grover V and Thirumal M 2001 Mater. Res. Bull. 361967

14. Gai P L, Thomas J M, Wright P A, Jones R H, Natarajan S, Chen J and Xu R 1992 J. Phys. Chem. 96 8206

15. Gai P L and Kourtakis K 1995 Science 267661

16. Vanderah T A, Roth R S, Siegrist T, Febo W, Loezos J M and Wong-Ng W 2003 Solid State Ionics 5 149 